\title{
Simulation-based lateral transshipment policy optimization for $s, S$ inventory control problem in a single-echelon supply chain network
}

\author{
Banu Y. Ekren*, Bartu Arslan \\ Department of Industrial Engineering, Yasar University, Turkey \\ banu.ekren@yasar.edu.tr, bartuarslan@yahoo.com
}

\section{ARTICLE INFO}

Article history:

Received: 15 February 2019

Accepted: 7 July 2019

Available Online: 16 September 2019

\section{Keywords:}

$s, S$

inventory

simulation

lateral transshipment

single echelon supply chain

AMS Classification 2010:

90B05, 90B06, 90B15

\begin{abstract}
Since it affects the performance of whole supply chain significantly, definition of correct inventory control policy in a supply chain is critical. Recent technological development enabled real time visibility of a supply network by horizontal integration of each node in a supply network. By this opportunity, inventory sharing among stocking locations is also possible in the effort of cost minimization in supply chain management. Hence, lateral transshipment gained popularity and studies seeking the best lateral-transshipment policy is still under research. In this study, we aim to compare different lateral-transshipment policies for an $s, S$ inventory control problem for a single-echelon supply chain network system. In this work, we consider a supply network with three stocking locations which may perform lateral transshipment among them when backorder takes place. We develop the simulation models of the systems in ARENA 14.5 commercial software and compare the performance of the policies by minimizing the total cost under a pre-defined fill rate constraint by using an optimization tool, OptQuest, integrated in that software. The results show that lateral transshipment works well compared to the scenario when there is no lateral transshipment policy in the network.
\end{abstract}

(cc) EY

\section{Introduction}

Because it affects performance of the whole chain significantly, inventory control policy in a supply chain is important. Due to recent increase in e-commerce, order profile has changed towards more product variety with less volume and decreased response time. For instance, same day delivery concept is considered as strategy in many distribution companies to increase customer satisfaction. The recent order profile caused more variability in orders throughout the supply chain. Therefore, inventory control problem emerged as a significant issue in supply chain to overcome this variability and increase the performance of the supply chain. In a study, it is pointed out that inventory cost constitutes the $40 \%$ of the total logistics cost for fast moving consumer goods supply chain [1]. Therefore, recently, there are numerous studies focusing on inventory control problems, e.g., exploring optimal policies [2-4] by testing new and practical policies such as lateral transshipment [5-7] and inventory routing policies [8].
Companies tend to carry inventory in practice, to reduce their total cost and improve their customer service. However, information sharing also enabling inventory sharing among locations by transshipments has been less frequent [9-10]. For providing an effective mechanism, transshipments are being made between stocking locations at the same echelon based on their available inventories and their distances to increase the efficiency of the network. For instance, allowing transshipments between stocking locations may lead cost reduction as well as service improvement resulting with customer satisfaction. In this study, we study a single-echelon supply chain network by focusing on determining the best lateral-transshipment policy from four pre-defined ones. Our goal is to minimize the total cost by determining the safety-stock and up-to levels of stocking locations under a predefined fill rate performance metric. In Fig. 1, the layout of the supply network is shown. Based on that, there are three stocking locations (depots) in which they have their own demand profiles. These stocking

\footnotetext{
${ }^{*}$ Corresponding author
} 
locations may share their inventories when a backorder takes place in one of the locations based on the predefined scenarios. The details of the sharing policy scenarios are explained in Section 3.4.

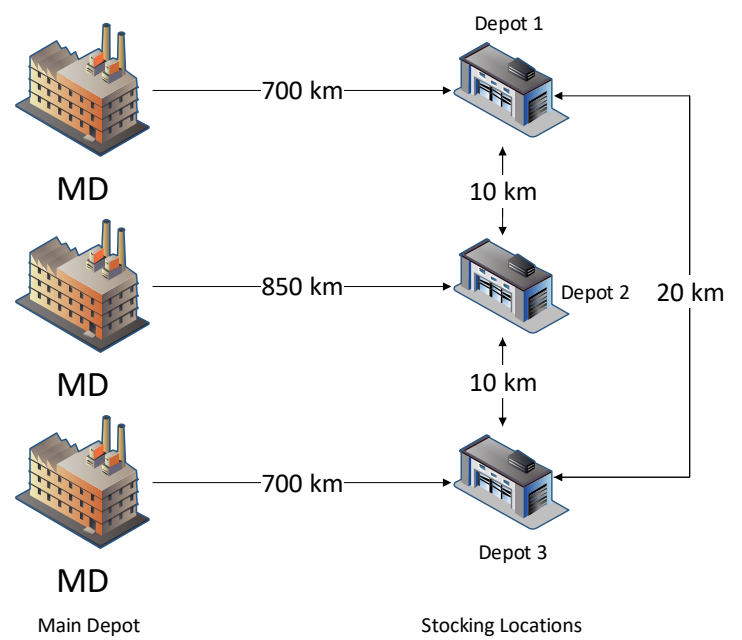

Figure 1. The studied single-echelon supply chain network.

In Fig. 1, we assume that the supply network's stocking locations are close to each other so that the backorder can be met instantaneously. Hence, we ignore the lead times for lateral transshipments, however, we consider a cost for these transshipments.

\section{Literature review}

Lateral transshipment can be defined as stock sharing policy among same echelon locations in an inventory network system. It is mostly motivated because that shorter lead times and decreased cost in redistribution of goods can be ensured compared to distribution from the main depot [11]. Recent comprehensive overviews on the problem are provided by [4] and [12]. In lateral transshipment mainly, there are two types of transshipment policies based on its timing: (1) reactive transshipments in response to an existing stock out [1315], (2) proactive transshipments to prevent the future stock out [16-18]. In this work, we study reactive transshipment policies in which lateral transshipment may take place when backorder occurs in a stocking location.

Generally, the studies focus on the decision of how the lateral transshipment will take place between the locations [19-21]. For instance, Axsäter [19] studies a single-echelon inventory problem having a number of parallel local warehouses with Poisson demand. He evaluates the proposed decision rule via simulation model and concludes that the suggested rule performs quite good. Çapar et al. [20] study a decision rule by coordinating inventory and transportation policies in a two-stage supply chain network. They present that on average, their proposed rule outperforms the other alternative policies. A new heuristic approach for inventory sharing problem via lateral transshipment is introduced by Tiacci and Saetta [21]. Their work show that the proposed heuristic approach works well for inventory balancing problem by lateral transshipment policies minimizing overall cost. A recent survey has also studied lateral transshipment problem for inventory models [4]. The interested reader can find further information in that review article.

The existing studies in the literature showed that transshipment is beneficial when the replenishment lead times are long from the upper echelon suppliers and when the stocking locations are close to each other at the same echelon level. This benefit increases drastically when backorder (shortage or penalty) cost is high. Recent transshipment studies explore different transshipment policies [20] by also investigating integration of proactive and reactive transshipment policies [22]. The existing studies show that when there is lateral transshipment policy in those networks, average cost is reduced by $11-17 \%$ compared to no lateral transshipment policy in that network [6].

The history of the $(s, S)$ inventory control policies goes back to 1950s. Arrow et al. [23] developed a simple model determining the best order-up-to-level and the re-order level as a function of demand distribution, setup and stock out costs. The model considers immediate replenishment assumption. Freeman [24] studied $(s, S)$ inventory policy with the inclusion of variable delivery time to derive the order size and the reordering point from an analytical perspective. Since then, lots of different variants of $(s, S)$ policies have been analyzed and a considerable research has accumulated [25-28] because of its simple and efficient applications. An $s, S$ inventory modelling application is shown by [29] which is a case study in a paint production company in Turkey.

The literature papers propose trial of new different transshipment policies as future study. Hence, different from the existing studies, we consider different four transshipment policies under reactive transshipment policy to test which one works better under the studied network. In the considered policies, based on the backorder amounts and the inventory levels of the other stocking locations, transshipments either take place or do not take place. Besides we compare the four transshipment policies among each other, we also compare these transshipment policies with the one when there is no lateral transshipment policy in the network.

\section{Problem definition and simulation modelling}

In this section, we provide the details of the studied inventory problem and the simulation modelling of the studied system with the assumptions.

\subsection{Problem definition}

In this paper, we study a single-item, one-echelon inventory problem in which items can be stored in three, $i=1,2,3$, stocking locations. Those stocking locations are assumed to be supplied by an upper echelon supplier (i.e., main depots) with infinite 
production capacity (see Fig. 1). In the model, it is assumed that demand for each stocking location $i$, arrives at the beginning of each period $t\left(d_{i t}\right)$. Demand, $d_{i t}$, is fully satisfied, if there is sufficient amount of inventory level at the depot $i$ at time $t, I_{i t}$. After fully satisfying the demand, at the end of the time, inventory is checked at stocking locations for determining whether an order will be given from the main depot. Based on the considered inventory control policy of $s$, $S$, if the inventory level $I_{\text {it }}$ is less than or equal to safety stock level, $s_{i}$, an order is placed for the stocking location $i$ at time $t$. The order quantity, $Q_{i t}$, is defined to be fulfilling the inventory level to up-to-levels of stocking locations, $S_{i}$. Hence, $Q_{i t}$ is equal to $S_{i}-I_{i t}$. In the models, it is assumed that there is truck (transporter) capacity in carrying products both from the main depot and in the lateral transshipments. A lead time from the main depot to the stocking locations, $L_{m i}$, is also considered. If the demand exceeds the current inventory level, backorder occurs. When backorder takes place, lateral transshipment may realize between stocking locations based on the pre-defined scenario detailed in Section 3.4. The backorder amount that could not be satisfied by lateral transshipment is included as backorder cost in the total cost calculations.

\subsection{Model notations}

The utilized notations for the parameters are provided below:

$b$ : backorder cost per demand,

$k \quad$ : number of stocking locations (i.e., $k=3$ )

$h \quad$ : holding cost per demand,

$l_{i j} \quad$ : a single truck's travel cost from stocking location $i$ to $j$ realizing lateral transshipment,

$t_{i} \quad$ : a single truck's transportation cost from the main depot to stocking location $i$,

$d_{i t} \quad$ : demand amount for stocking location $i$ at time $t$,

$b_{i t}$ : after lateral transshipments, backorder amount occurred at stocking location $i$ at time $t$

$I_{i t} \quad$ : inventory level of stocking location $i$, at the end of time $t$

$d_{m i} \quad$ : distance from the main depot to stocking location $i(\mathrm{~km}$.),

$d_{i j} \quad$ : distance from stocking location $i$ to $j$,

$L_{m i} \quad$ : lead time from the main depot to stocking location $i$

$L_{i j} \quad$ : lead time from stocking location $i$ to stocking location $j$,

$C_{m} \quad$ : Truck capacity for main depot

$C_{t} \quad$ : Transporter capacity in lateral transshipment

In the above variables, $h$ and $b$ values are assumed to be, $\$ 1 /$ demand and $\$ 5 /$ demand, respectively. $L_{m i}$ is set to: $L_{m 1}=1.5$ days; $L_{m 2}=1.75$ days; $L_{m 3}=1.5$ days and $L_{i j}$ values are ignored. Demand for stocking locations is considered to be same, stochastic and normally distributed: $N(100,20)$.

Besides the above variables, we also consider the below decision variables for optimization.

$s_{i} \quad$ : safety stock level of stocking location $i$;

$S_{i} \quad$ : up-to-level of stocking location $i$;

$n_{\text {mit }} \quad$ : number of trucks sent from the main depot to the stocking location $i$, at time $t$,

$n_{i j t} \quad$ : number of transporters sent from stocking location $i$ to $j$, at time $t$,

$Q_{i t} \quad$ : order quantity of stocking location $i$, from the main depot at the end of time $t$,

$q_{i j t}$ : amount of lateral transshipment from stocking location $i$ to stocking location $j$, at time $t$,

It should be noticed that in an $\left(s_{\mathrm{i}}, S_{\mathrm{i}}\right)$ inventory model, the a stocking location $i$ (i.e. depot) places an order whenever its inventory level $\left(I_{i t}\right)$ decreases to a level less than the reorder level, $s_{\mathrm{i}}$. At the end of each period $t$, the order quantity $Q_{\text {it }}$ is calculated by Eq. (1) providing that the inventory is raised to an order-up-to level $S_{\mathrm{i}}$ :

$$
Q_{i t}=\left\{\begin{array}{c}
S_{i}-I_{i t} \text { if } I_{i t} \leq s_{i} \\
0, \text { otherwise }
\end{array}\right.
$$

Total cost (TC) is calculated by the Eq. (2) where $T$ is the total simulation run time (i.e. 365 days) and $k$ is the total number of stocking locations (i.e. $k=3$ ):

$$
\begin{aligned}
& T C=\sum_{t=1}^{T} \sum_{i=1}^{k} \sum_{j \neq i}^{k}\left[\left(h \times I_{i t}\right)+\left(b \times b_{i t}\right)+\right. \\
& \left.\left(n_{m j t} \times t_{i}\right)+\left(n_{i j t} * l_{i j}\right)\right]
\end{aligned}
$$

where $n_{m i t}, n_{i j t}$, and $t_{\mathrm{i}}, l_{\mathrm{ij}}$ values are computed by the below (3)-(6) equations:

$$
\begin{gathered}
n_{m i t}=Q_{i t} / C_{m} \\
n_{i j t}=q_{i j t} / C_{t} \\
t_{i}=d_{m i} \times \$ 0.4 / \mathrm{km} \\
l_{i j}=d_{i j} \times \$ 0.2 / \mathrm{km}
\end{gathered}
$$

\subsection{Simulation model assumptions}

The inventory problem is simulated by the assumptions summarized below.

- In the simulation models, three stocking locations are considered where lateral transshipments may take place.

- We consider four different pre-defined lateral transshipment policies $\left(P_{1}, P_{2}, P_{3}\right.$ and $\left.P_{4}\right)$ to compare their optimal results.

- Demand arrive each stocking location at the beginning of each day with normal distribution and the inventory levels are checked at the end of each day after demands are met from the inventory and lateral transshipments are completed.

- In total cost calculations, holding, transportation, 
transshipment and backorder costs are considered.

- A new order is not sent to the main depot by the stocking locations until the previous ones arrive.

- Holding and backorder costs are considered to be $\$ 1$ and $\$ 5$ per demand, respectively.

- In transportation and transshipment cost calculations, we considered the distance (in $\mathrm{km}$.) travelled in the network. For instance, travelling cost of a truck and lateral transshipment transporter is considered to be $\$ 0.4 / \mathrm{km}$ and $\$ 0.2 / \mathrm{km}$, respectively.

- There is truck capacity constraint for both main depot transportation and lateral-transshipments which are considered to be 100 products/truck $\left(C_{\mathrm{m}}\right)$ and 25 products/transporter $\left(C_{\mathrm{t}}\right)$, respectively.

- It is assumed that there is infinite number of trucks and transporters in the system.

- Upper echelon supplier has infinite amount of items.

- The run length of simulation models is considered to be one year with 60 days of warm-up period for each scenario.

- To find out the optimal levels of $s_{\mathrm{i}}, S_{\mathrm{i}}$, we considered the minimization of total cost as objective function.

- Ten independent replications are completed in each scenario run.

- In the optimization, fill rate constraint is considered to be 0.95 .

In the fill rate assumption, we considered that for instance, if a customer requests 100 units for demand, but the current inventory level is 80 units, then the fill rate is $80 \%$. In the simulation models, because it is a popular and commonly utilized variance reduction technique, we used Common Random Numbers (CRN) variance reduction technique. In that technique, the same random number stream is used for different scenario configurations so that variance reduction is ensured.

\subsection{Lateral transshipment policies}

As mentioned previously, we determine four different lateral-transshipment policies to test how the lateral transshipment policies affect the inventory control problem and which works better based on the optimized total costs.

In each policy, first the arriving demands are satisfied by the current inventory in each stocking location. Then, a backorder existence is checked in the stocking locations of 1, 2 and 3, in sequence. If backorder occurs in a stocking location $i$ at time $t\left(b_{\mathrm{it}}\right)$, then a lateral transshipment may take place for this location based on the below pre-defined policies:

Transshipment Policy 1, $\left(\mathrm{P}_{1}\right)$ :

1 - inventory availability is checked starting from the nearest stocking location $j$ (where $i \neq j$ ).

2 - backorder amount $\left(b_{i t}\right)$ is started to be met by transshipments from the nearest stocking locations in order. For instance, in the nearest stocking location, if the existence inventory amount does not meet the backorder amount then the remaining backorder is met from the following nearest stoking locations.

3- after transshipping all available inventories, if there is still a remaining backorder amount, then it is demanded from the upper supplier (main depot) at the end of the day.

4- the remaining amount of backorder that is supplied from the upper echelon is incurred as backorder cost in the total cost calculation.

\section{Transshipment Policy 2, $\left(\mathrm{P}_{2}\right)$ :}

1 - inventory availability is checked be starting from the nearest stocking location $j$ (where $i \neq j$ ) whether single lateral transshipment can be done or not.

2 - if available inventory at stocking location $j$ at time $t$ is larger than the backorder amount $b_{i t}$, all the backorder is transshipped from this nearest stocking location $j$. Otherwise, the remaining nearest stocking locations' inventory levels are checked until it is found that there is available inventory level as backorder amount $b_{i t}$.

3- if none of the stocking locations have enough inventory level as the backorder amount, $b_{\mathrm{i}}$, then no lateral transshipment occurs and the backorder amount is demanded from the upper supplier at the end of the day.

4- the amount of backorder supplied from main depot is incurred as backorder cost in the total cost calculation.

\section{Transshipment Policy 3, $\left(P_{3}\right)$ :}

In this policy, first the availability of implementing $P_{2}$ is searched. Namely, the availability of meeting all the backorder amount at time $t, b_{i t}$, by a single lateral transshipment is searched. However, if there is no any stocking location $j$ having $b_{i t}$ amount of inventory level $\left(I_{\mathrm{jt}}<b_{\mathrm{it}}, \forall j\right)$, then the total amount of inventory level in all stocking locations $j$ at that time $t$ where $i \neq j$ is calculated $\left(\sum_{j \neq i} I_{j t}\right)$. If the total inventory levels in the stocking locations is larger than equal to $b_{i t}\left(\sum_{j \neq i} I_{j t} \geq\right.$ $b_{i t}$ ) then lateral transshipments take place starting from the nearest stocking locations until the $b_{i t}$ amount is met. Otherwise, no lateral transshipment occurs and all the $b_{i t}$ amount is met from the main depot.

\section{Transshipment Policy 4, $\left(P_{4}\right)$ :}

This policy is the combination of policies $P_{1}$ and $P_{2}$. Namely, first the availability of implementing the $P_{2}$ is searched. If $P_{2}$ cannot be implemented, in other words if the backorder amount at stocking location $i$ at time $t$, cannot be met by a single lateral transshipment then $P_{1}$ is implemented.

Policy 5, $\left(\boldsymbol{P}_{5}\right)$ :

Except the transshipment policies defined above, we also consider an inventory control system where no 
lateral transshipments among the stocking locations take place.

\subsection{Simulation model and OptQuest results}

As an example, simulation flow chart of the developed ARENA model for Policy 1 and its OptQuest result's screenshots are shown by Figs. 2 and 3, respectively.

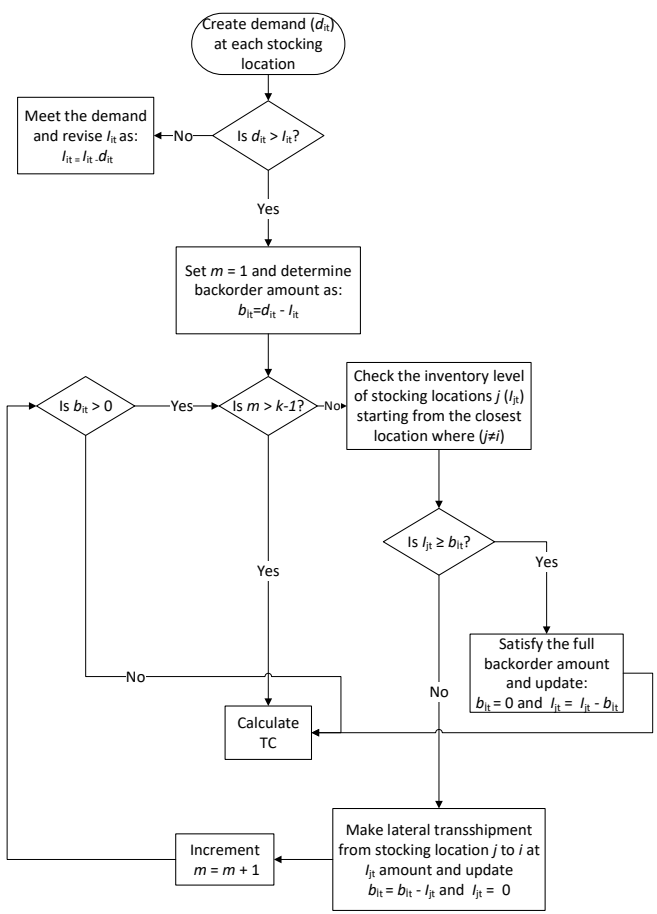

Figure 2. Flowchart of the simulation model for Policy 1

In an $s, S$ inventory problem optimization, Kleijnen and Wan [30] showed the efficiency of the OptQuest optimization tool in the ARENA software. This optimization tool is a heuristic-based optimization tool combining the meta-heuristics of tabu search, neural networks, and scatter search into a single search heuristic [30]. It allows the user to explicitly define integer and linear constraints for the simulation inputs. Initially, it also requires the user to specify the lower, suggested, and the upper values for the decision variables to be optimized. The suggested values are for determining the starting points in the search procedure for $s_{\mathrm{i}}$ and $S_{\mathrm{i}}$. In an effort to find a better result, first an initial optimization is run by heuristically determined suggested solution. Then, we utilize this initial optimization's result as suggested solution in the second optimization run.

\subsection{Simulation results}

Fig. 3 shows the OptQuest result namely the optimal $s_{\mathrm{i}}$, $S_{\mathrm{i}}$ values for Policy 1 . According to that, the optimal $s_{i}$, $S_{\mathrm{i}}$ values for $P_{1}$ are found to be $(95,200),(62,100)$, $(265,360)$ for $i=1,2,3$, respectively. The total cost is $\$ 483,694$ at those levels.
The optimal $s_{\mathrm{i}}, S_{\mathrm{i}}$ levels obtained by the OptQuest tool based on the pre-defined policies $P_{1}-P_{5}$ are summarized in Table 1 and Table 3 . The output results for Table 1 are given by Table 2 .

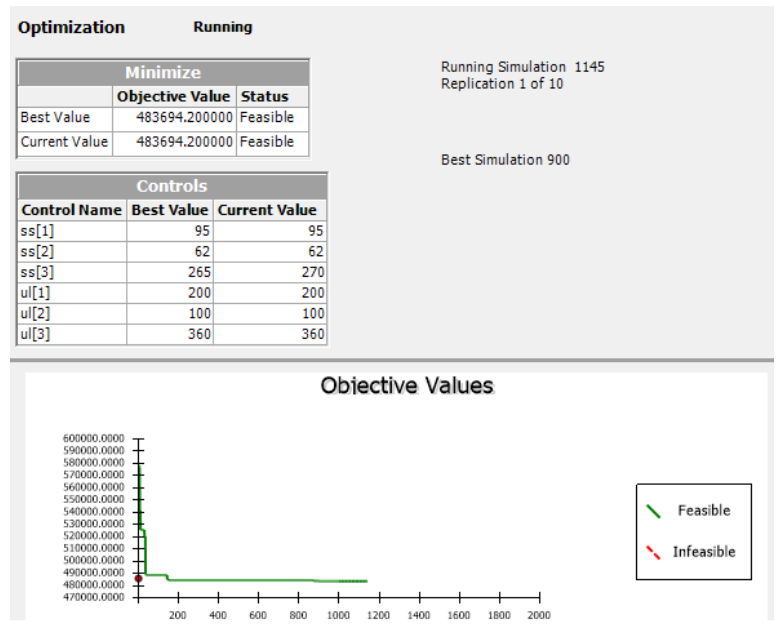

Figure 3. $s_{i}, S_{\mathrm{i}}$ values of $P_{1}$ in ARENA OptQuest

Table 1. $s, S$ values of policies.

\begin{tabular}{crrllrl}
\hline Policy & \multicolumn{1}{c}{$\boldsymbol{s}_{\boldsymbol{1}}$} & \multicolumn{1}{c}{$\boldsymbol{S}_{\boldsymbol{2}}$} & \multicolumn{1}{l}{$\boldsymbol{S}_{\mathbf{3}}$} & $\boldsymbol{S}_{\boldsymbol{1}}$ & \multicolumn{1}{c}{$\boldsymbol{S}_{\boldsymbol{2}}$} & $\boldsymbol{S}_{\mathbf{3}}$ \\
\hline 1 & 95 & 62 & 265 & 200 & 100 & 360 \\
2 & 143 & 63 & 255 & 304 & 96 & 298 \\
3 & 165 & 63 & 278 & 294 & 99 & 300 \\
4 & 61 & 40 & 210 & 200 & 99 & 391 \\
5 & 178 & 189 & 167 & 314 & 283 & 283 \\
\hline
\end{tabular}

Once again, Table 2 shows total cost and fill rate results based on optimal Table 1 results.

Table 2. Total costs and fill rates of policies.

\begin{tabular}{ccc}
\hline Policy & TC & Fill rate \\
\hline 1 & $\$ 483,694$ & 0.9535 \\
2 & $\$ 512,941$ & 0.9501 \\
3 & $\$ 509,339$ & 0.9546 \\
4 & $\$ 492,445$ & 0.9523 \\
5 & $\$ 580,673$ & 0.9508 \\
\hline
\end{tabular}

Table 3 shows, the frequency of lateral transshipments took place among the stocking locations at the Table 1 values, optimal levels of $s_{\mathrm{i}}, S_{\mathrm{i}}$ found by OptQuest.

Table 3. Lateral transshipment frequency among the stocking locations.

\begin{tabular}{crrrl}
\hline Policy & $\boldsymbol{A v g} \sum \boldsymbol{n}_{\boldsymbol{l j}}$ & $\boldsymbol{A v g} \sum \boldsymbol{n}_{\boldsymbol{j} j}$ & $\boldsymbol{A v g} \sum \boldsymbol{n}_{\mathbf{3} j}$ & Total \\
\hline 1 & 765.6 & 106.6 & 886.4 & $1,758.6$ \\
2 & 860.6 & 5.7 & 517.9 & $1,384.2$ \\
3 & 904.9 & 9.3 & 563.9 & $1,478.1$ \\
4 & 541.2 & 23.4 & $1,069.1$ & $1,633.7$ \\
Total & $\mathbf{3 , 0 7 2 . 3}$ & $\mathbf{1 4 5}$ & $\mathbf{3 , 0 3 7 . 3}$ & \\
\hline \multicolumn{5}{r}{}
\end{tabular}

Table 4 illustrates the frequency of transportation taking place from the main depot to the stocking locations in the scenarios of $P_{1}-P_{4}$ at the Table 1 values, the optimal levels of $s_{\mathrm{i}}, S_{\mathrm{i}}$ found by OptQuest. 
Table 4. Transportation frequency from main depot to stocking locations.

\begin{tabular}{crrrr}
\hline Policy & $\sum \boldsymbol{n}_{\boldsymbol{m} \boldsymbol{1}}$ & $\sum \boldsymbol{n}_{\boldsymbol{m} \mathbf{2}}$ & $\sum \boldsymbol{n}_{\boldsymbol{m} \boldsymbol{3}}$ & $\sum \boldsymbol{n}_{\boldsymbol{m} \boldsymbol{i}}$ \\
\hline 1 & 364.6 & 182.9 & 582.7 & $1,130.2$ \\
2 & 536.1 & 182.9 & 488.2 & $1,207.2$ \\
3 & 532.6 & 182.9 & 491.0 & $1,206.5$ \\
4 & 335.8 & 181.7 & 625.4 & $1,142.9$ \\
5 & 438.4 & 417.0 & 413.6 & $1,269.0$ \\
\hline
\end{tabular}

Table 5 illustrates the total transportation and holding costs based on lateral transshipment policies.

Table 5. Transportation and holding costs of policies.

\begin{tabular}{crr}
\hline Policy & $\sum$ Trans. Cost & \multicolumn{1}{c}{$\sum$ Holding Cost } \\
\hline 1 & $\$ 327,430$ & $\$ 122,680$ \\
2 & $\$ 348,990$ & $\$ 129,600$ \\
3 & $\$ 348,794$ & $\$ 128,650$ \\
4 & $\$ 330,914$ & $\$ 127,590$ \\
5 & $\$ 380,340$ & $\$ 170,020$ \\
\hline
\end{tabular}

In Table 1, we observe optimal $s_{i}, S_{i}$ levels and total cost (TC) values in columns 1-7 in order. We also illustrate the obtained fill rate at the last column. The findings from Tables 1-5 are summarized below:

- It is observed that TC is always smaller when there is any lateral transshipment policy in the network. Note that TC in $P_{5}$ is the largest one in Table 2.

- It is observed that the minimum cost is obtained by $P_{1}, P_{4}, P_{3}, P_{2}$ in sequence.

- By Table 1, it is noted that when there is any lateral transshipment policy in the network, stocking location 2 carries lower inventory ( $s, S$ levels) than the other stocking locations. This is probably due to that the second stocking location is the furthest location to the main depot. This stocking location tends to decrease the number of transportations from the main depot by decreasing the frequency of lateral transshipments to the other locations. This result can also be validated in Table 3 that $\sum n_{2 j}=$ 145 which is almost $1 / 20$ of the other transshipment frequencies: 3,072 and 3,037. It is also verified by Table 4 that $\sum n_{m 2}$ values are relatively low compared to the others.

- From Table 3, it can be observed that maximum lateral transshipment frequencies occur in $P_{1}, P_{4}$, $P_{3}, P_{2}$ in sequence, showing that there is negative correlation between TC and lateral transshipment frequency. Namely, when total cost increases, lateral transshipment cost decreases in the policies.

- From Table 4, we observe that the least transportation frequency from the main depot took place in $P_{1}$. Since this policy has the least TC, this may mean that the highest lateral transshipment frequency might take place in this policy. This can also be verified by Table 3 that the highest lateral transshipment frequency happened in $P_{1}(1,759)$.

- In Table 4, since there is no lateral transshipment, the highest transportation frequency from the main depot took place in $P_{5}$.

\section{Conclusion}

In this study, we compare different (i.e. four) lateraltransshipment policies in an $s, S$ inventory control problem of a single-echelon supply chain network system in which there are three stocking locations. By the recent technological development, real time visibility of a supply network by horizontal integration of each node in a network is possible. By this opportunity, lateral transshipment gained popularity and studies seeking the best lateral-transshipment policy is still under research. In this work, we aim to contribute to literature by considering different lateral transshipment policies in a supply network and comparing their performances by optimizing their objective functions, total cost. We develop the simulation models of the systems in ARENA 14.5 commercial software and compare the performances of them by minimizing the total cost under a pre-defined fill rate constraint (i.e., 95\%) by using OptQuest tool in this software. The results show that lateral transshipment works well for the studied supply system when it is compared with the scenario that there is no lateral transshipment policy in the network. It is observed that the minimum cost is obtained by the policies: $P_{1}, P_{4}, P_{3}, P_{2}$ in sequence.

Also, we noted that trial of different lateral transshipment policies under different supply network designs as well as parameter values (e.g. backlogging cost) and layout of chain is promising to be investigated as a future study.

\section{References}

[1] Cachon, G., \& Terwiesch, C. (2006). Matching supply with demand. McGraw-Hill, Inc.

[2] Arrow, K. J., Harris, T., \& Marschak, J. (1951). Optimal Inventory Policy. Econometrica,19(3), 250-272.

[3] Waller, M., Williams, B.D., \& Tokar, T. (2008). A Review of Inventory Management Research in Major Logistics Journals: Themes and Future Directions. The International Journal of Logistics Management, 19(2), 212-232

[4] Bushuev, M.A., Guiffrida, A., Jaber, M.Y., \& Khan, M. (2015). A Review of Inventory Lot Sizing Review Papers. Management Research Review, 38(3), 283-298.

[5] Paterson, C., Kiesmuller, G., Teunter, R., \& Glazebrook, K. (2011). Inventory models with lateral transshipments: A review. European Journal of Operational Research, 210(2), 125-136.

[6] Pan, S., Nigrelli, M., Ballot, E., Sarraj, R., \& Yang, Y. (2015). Perspectives of Inventory Control Models in the Physical Internet: A Simulation Study. Computers \& Industrial Engineering, 84, 122-132.

[7] Yang, Y., Pan, S., \& Ballot, E. (2015). Mitigating supply chain disruptions through interconnected 
logistics services in the Physical Internet International. Journal of Production Research, 55(14), 3970-3983.

[8] Bertazzi, L., \& Speranza, M.G. (2012). Inventory Routing Problems: An Introduction. EURO Journal on Transportation and Logistics, 1(4), 307-326

[9] Ozdemir D., Yucesan, E., \& Herer, Y.T. (2006). Multi-location transshipment problem with capacitated transportation. European Journal of Operational Research, 175, 602-621.

[10] Ekren, B.Y. \& Heragu, S.S. (2008). Simulation Based Optimization of Multi-Location Transshipment Problem with Capacitated Transportation. In Proceedings of the 2008 Winter Simulation Conference, edited by S. J. Mason et al., 2632-2638. Piscataway, New Jersey: IEEE.

[11] Allen, S.C. (1958). Redistribution of total stock over several user locations. Naval Research Logistics Quarterly, 5(4), 337-345.

[12] Seidscher, A., \& Minner, S. (2013). A Semi-Markov decision problem for proactive and reactive transshipments between multiple warehouses. European Journal of Operational Research, 230(1), $42-52$.

[13] Krishnan, K., \& Rao, V. (1965). Inventory control in $N$ warehouses. Journal of Industrial Engineering, 16, 212-215.

[14] Robinson, L.W. (1990). Optimal and approximate policies in multiperiod, multilocation inventory models with transshipments. Operations Research, $38(2), 278-295$.

[15] Olsson, F. (2010). An inventory model with unidirectional lateral transshipments. European Journal of Operational Research, 200(3), 725-732.

[16] Diks, E.B., \& de Kok, A.G. (1996). Controlling a divergent 2-echelon network with transshipments using the consistent appropriate share rationing policy. International Journal of Production Economics, 45(1-3), 369-379.

[17] Diks, E.B., \& de Kok, A.G. (1998). Optimal control of a divergent multi-echelon inventory system. European Journal of Operational Research, 111(1), 75-97.

[18] Tagaras, G., \& Vlachos, D. (2002). Effectiveness of stock transshipment under various demand distributions and nonnegligible transshipment times. Production and Operations Management, 11(2), 183-198.

[19] Axsäter, S. (2003). A New Decision Rule for Lateral Transshipments in Inventory Systems. Management Science, 49(9), 1168-1179.

[20] Capar, I., Eksioglu, B. \& Geunes, J. (2011). A decision rule for coordination of inventory and transportation in a two-stage supply chain with alternative supply sources. Computers \& Operations Research, 38(12), 1696-1704.
[21] Tiacci, L., \& Saetta, S. (2011). A heuristic for balancing the inventory level of different locations through lateral shipments. International Journal of Production Economics, 131(1), 87-95.

[22] Paterson, C., Teunter, R. \& Glazebrook, K. (2012). Enhanced lateral transshipments in a multi-location inventory system. European Journal of Operational Research, 221(2), 317-327.

[23] Arrow, K.J., Harris, T., \& Marschak, J. (1951). Optimal Inventory Policy. Econometrica, 9(3), 250272.

[24] Freeman R. (1957). $S$ s Inventory Policy with Variable Delivery Time. Management Science, 3(4), 431-434.

[25] Axsäter, S. (2015). Inventory Control. International Series in Operations Research \& Management Science. Springer International Publishing, $3^{\text {rd }}$ Ed., Switzerland.

[26] Bashyam, S., \& Fu, M.C. (1998). Optimization of ( $s$, $S$ ) Inventory Systems with Random Lead Times and a Service Level Constraint. Management Science, 44(12), part-2, 243-256.

[27] Sethi, S., \& Cheng, F. (1997). Optimality of $(s, S)$ Policies in Inventory Models with Markovian Demand. Operations Research, 45(6), 931-939.

[28] Silver E.A., Pyke D.F., \& Peterson R. (1998). Inventory management and production planning and scheduling. New York: Wiley.

[29] Ekren, B.Y. \& Ornek, A. (2015). Determining Optimum $(s, S)$ Levels of Floor Stock Items in a Paint Production Environment. Simulation Modelling Practice and Theory, 57, 133-141.

[30] Kleijnen, J.P.C., \& Wan, J. (2007). Optimization of simulated systems: OptQuest and alternatives. Simulation Modelling Practice and Theory, 15(3), 354-362.

Banu Y. Ekren is a full professor in the department of Industrial Engineering, at Yasar University, in Izmir, Turkey. She got her Ph.D., from University of Louisville in the Dept. of Industrial Engineering, in Kentucky, USA. Her research focus is on warehousing, stochastic and simulation modelling, supply chains, simulation-based optimization, and design of automated warehousing. Banu Y. Ekren holds associate professor position at her university and teaches simulation, stochastic modelling and facility logistics courses at the undergraduate level. She has several simulation-based journal and book chapter publications.

https://orcid.org/0000-0001-6491-1389

Bartu Arslan is an industrial engineer, graduated from the Department of Industrial Engineering, at Yasar University in Izmir, Turkey. He worked as a fellow under Dr. Banu Y. Ekren's supervision for a research project funded by TUBITAK focusing on agent-based simulation modelling of an automated warehousing system. His research interests include applications of simulation- 
optimization in supply chain, logistics, production, and warehousing. Arslan would like to do academic career in Industrial Engineering specifically focusing on dynamic modelling approaches in simulation.

(iD) https://orcid.org/0000-0003-2114-767X

An International Journal of Optimization and Control: Theories \& Applications (http://ijocta.balikesir.edu.tr)

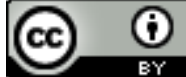

This work is licensed under a Creative Commons Attribution 4.0 International License. The authors retain ownership of the copyright for their article, but they allow anyone to download, reuse, reprint, modify, distribute, and/or copy articles in IJOCTA, so long as the original authors and source are credited. To see the complete license contents, please visit http://creativecommons.org/licenses/by/4.0/. 